
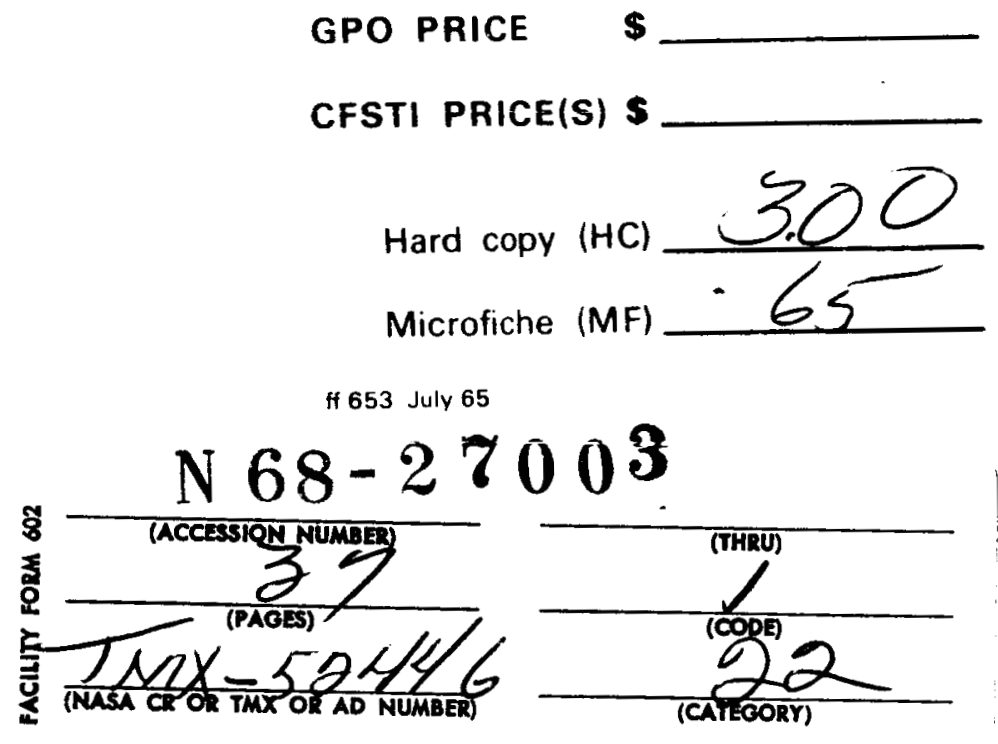

\title{
A NUCLEAR THERMIONIC SPACE POWER CONCEPT \\ USING ROD CONTROL AND HEAT PIPES
}

by John L. Anderson and Edward Lantz

Lewis Research Center

Cleveland, Ohio

TECHNICAL PAPER proposed for presentation at

14th Annual Meeting

the American Nuclear Society

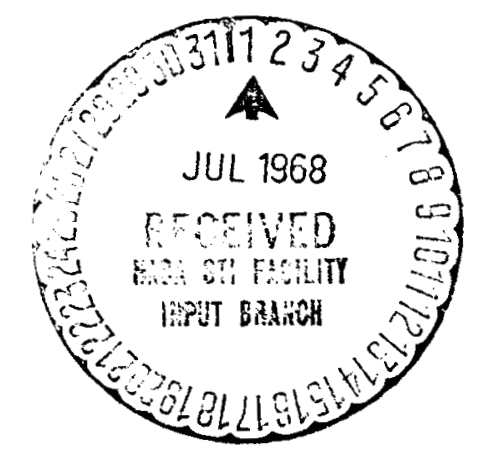

- Toronto, Canada, June 9-13, 1968 


\section{A NUCLEAR THERMIONIC SPACE POWER CONCEPT USING ROD CONTROL AND HEAT PIPES by John L. Anderson and Edward Lantz Lewis Research Center Cleveland, Ohio}

TECHNICAL PAPER proposed for presentation at 14th Annual Meeting of the American Nuclear Society Toronto, Canada, June 9-13, 1968 


\title{
A NUCLEAR THERMIONIC SPACE POWER CONCEPT
}

\section{USING ROD CONTROI AND HEAT PIPES}

by John I. Anderson and Edward Lantz

\section{Lewis Research Center}

National Aeronautics and Space Administration

Cleveland, Ohio

\begin{abstract}
A nuclear reactor space power system using out-of-pile thermionic diodes, heat pipes, and a dual central rod type of reactivity control was investigated. Emphasis is on the neutronic aspects and general feasibility of the concept. In this concept heat is transferred from the reactor core to the thermionic diodes by layers of radial heat pipes stacked alternately with slabs of fuel. For this out-of-pile concept, which would supply $130 \mathrm{kWe}$, the reactor can be considerably smaller than the equivalent reactor with in-pile diodes, when used with a shadow shield.
\end{abstract}




\section{A NUCLEAR THERMIONIC SPACE POWER CONCEPT USING ROD :CONIROI AIN HEAT PIPES \\ by John L. Anderson and Edward Lantz \\ Lewis Research Center \\ National Aeronautics and Space Administration \\ Cleveland, Ohio \\ SUMMARY}

A nuclear space power system using out-of-core thermionic diodes and cooled by heat pipes has been studied. The purpose of this study is to establish a consistent set of specifications for the power system; the emphasis is on neutronics and general feasibility. The power system uses a cylindrical fast spectrum reactor fueled with uranium-233 nitride and reflected by molybdenum. The reactor, including the reflector, is 0.355 meter in diameter and 0.51 meter long. Heat is: transferred from the reactor core to thermionic diodes by layers of radial heat pipes stacked alternately with slabs of fuel.

Each annular layer of fuel or heat pipes is formed from sectorshaped elements. Outside the radial reflector the diodes are placed concentrically around the heat pipes. All 24 heat pipes on an axial level terminate in a radiator which takes the form of a flat disk. The reactivity control system consists of a central rod and a concentric tubular sheath of boron-10 carbide located along the cylindrical axis of the reactor. The rod and sheath are separated and cooled by a concentric annular heat pipe.

The axial power is tailored by nonuniform distribution of fuel to provide approximately the same heat flux to each of the 10 axial layers of heat pipes. This tailoring, to within 5\%, allows more uniform 
performance of the thermionic diodes. Parameters representing the state of the art are used to set performance levels. About 860 diodes convert the thermal output power of 1.74 MW to an electric power output of about $130 \mathrm{kWe}$, an overall efficlency of $7.5 \%$. It is found that the reactor of this out-of-pile concept can be considerably smaller than the equivalent reactor with in-pile diodes, when used with a shadow shield. 


\section{INTRODUCTION}

System studies, such as in Ref. 1, have shown that above a power level of $100 \mathrm{kWe}$, a nuclear reactor is the most promising heat source. Several conversion systems, which convert the thermal energy of a nuclear reactor to electrical energy while operating in the space environment, are currently being examined. However, none of these conversion systems (gas Brayton cycle, liquid metal Rankine cycle, or

in-pile thermionic diodes) demonstrates an obviously superior performance.

This work deals with a thermionic system, but one which has the thermionic diodes outside rather than inside the reactor core. Outside the reactor core the radiation environment is not so harsh and thus the nuclear degradation of the diodes is less than if they were inside the core. The feasibility and potential performance of out-ofpile thermionic diodes is particularly promising when considered in conjunction with the heat pipe, an efficient and simple method of high heat transference. Furthermore, this almost isothermal heat transfer property of the heat pipe allows the out-of-pile diode emitters to be at about the same temperature as the emitters of in-pile diodes.

Two out-of-pile thermionic space power concepts (refs. 2 and 3 ), each cooled by heat pipe, have been previously described. Reference 2 describes a concept which uses 120 heat pipes to provide a power output of $36 \mathrm{kWe}$. The design in Ref. 3 is more ambitious in that it would supply $10 \mathrm{MWe}$ but with a corresponding increase to several thousand heat pipes. 
This difference in power levels reflects the wide range of electrical power levels that will be required for the variety of future space missions. In particular, power in the $100 \mathrm{kWe}$ range will be required for such specific missions as: a satellite in synchronous orbit used for direct broadcast to individual homes, 20-40 man orbital space stations, a modest lunar base, and propulsive power for unmanned deep space probes.

The present work examines a thermionic heat pipe space power source similar to that in Ref. 2. However, this current concept uses a more conventional (absorber rods) reactivity control system and has a higher power output $(130 \mathrm{kWe})$. The purpose of this work is to establish a consistent set of specifications for such a thermionic heat pipe space power system. The emphasis of the study is on the neutronics and general feasibility of the system; thus, the scope is such that only a cursory assessment of nonneutronics aspects is made.

DESCRIPTION OF THERMIONIC SPACE POWER SYSTEM

The components of a thermionic power system may be categorized into a heat source and its control system, a thermionic conversion system, and cooling systems for the waste heat. The heat source for this power system is a nuclear reactor which is controlled by neutron absorbing control rods. The reactor is cooled by heat pipes which transfer the heat radially out of the core to the thermionic conversion system. Figure $I$ is a cutaway view of the general reactor configuration. Upon emerging from the radial reflector the heat pipes heat the emitters of the thermionic diodes. The collectors of the diodes are cooled by another set of heat pipes which lead to radiators. Following is a description of these components for this concept. 
The Reactor

A cylindrical fast spectrum nuclear reactor, fueled by uranium-233 nitride $\left(U^{233} N\right)$ is used as the heat source. Alternate fuels (uranium235 nitride and plutonium-239 nitride) were compared and the results are presented in appendix $A$. The $U^{233} N$ reactor has a length of $51.0 \mathrm{~cm}$ and a diameter of $35.5 \mathrm{~cm}$ including the thickness of the molybdenum reflectors. The fuel is clad with $0.05 \mathrm{~cm}$ of tungsten (W).

The reactor core consists of alternating fuel and heat pipe slabs or disks. The thickness of each of the fuel disks is limited by the power density and heat transfer characteristics of the fuel since the centerline temperature must remain below the melting point of $\mathrm{U}^{233} \mathrm{~N}$. The reactor is reflected axially on each end by $10 \mathrm{~cm}$ of molybdenum (Mo) and radially by a $6-\mathrm{cm}$ thick annulus of Mo.

Each disk of fuel or heat pipes is composed of 24 units, each unit being a $15^{\circ}$ sector (fig. 1). It should be possible to fabricate, inspect, and test these pie-shaped sectors individually prior to putting them together in an assembly. On assembly each layer of fuel sectors would be oriented, with respect to an adjacent heat pipe layer, so that each fuel surface would be cooled by two heat pipes (fig. 2). This staggered orientation would allow the heat load of a failed heat pipe to be carried by the two flanking heat pipes. With such a failure in mind each fuel sector contains some tungsten to improve the thermal conductivity of the fuel elements. By proper distribution of this tungsten within a fuel element it should be possible to insure the integrity of the fuel elements even in the event of a failure of nonadjacent heat pipes. 
Furthermore, each fuel sector contains some void volume to allow for fuel expansion and to collect the gaseous fission products. Venting would occur through a molecular sieve or an orifice to out-of-pile chambers which are radiantly cooled. Such a venting system is described in Ref. 2. The void zones which would separate each fuel sector into two pieces also contain nitrogen to provide the nitrogen. overpressure required to prevent dissociation of the fuel. Reference 4 indicates that an overpressure of $2-3$ atmospheres $\left(20.3-30.4 \mathrm{~N} / \mathrm{cm}^{2}\right)$ is sufficient to prevent dissociation. The reference further quotes the melting point of $\mathrm{U}^{233} \mathrm{~N}$ as $3120 \mathrm{~K}$.

The Heat Pipes

The heat pipe is a simple, highly efficient device capable of transporting several hundred times the heat energy per unit weight as metals such as copper or silver (ref. 5). As previously stated, the almost isothermal operation of the heat pipe is particularly useful in a thermionic conversion system because it allows the thermionic diodes to be placed outside the reactor core in a less severe environment and still operate at about the heat pipe evaporator or in-pile diode emitter temperature.

Figure 3 is a schematic drawing of the heat pipe illustrating the basic features and operation. Within the closed shell of a heat pipe a liquid working fluid and some sort of capillary action pump (e.g., wire mesh, porous wick, or longitudinal grooves) comprise the heat transfer loop. When heat is added to the evaporator end of the heat pipe the liquid ther is vaporized, causing the local pressure to 
increase. The vapor then flows through the pipe under the pressure gradient. At the colder end of the pipe the vapor condenses and the liquid is returned to the evaporator by capillary pumping in the wick material.

Heat pipes have been developed and experimentality examined at Los Alamos Scientific Laboratory; some results are reported in Réf: 6 . Tests were performed with various combinations of wick geometry and working fluids. Theoretical analysis of heat pipe operation may be found in Ref. 7 and 8 . The other conversion systems mentioned previously require electromagnetic pumping. A comparison of a potential heat pipe system with an electromagnetic pumped loop system is given in table $I$.

In this concept, the heat pipe wall material is tantalum, $0.05 \mathrm{~cm}$ thick. Tantalum was chosen because it appears to have about the same or greater neutron capture cross section than other refractory alloys. Thus, it represents a conservative assumption with regard to the neutronic properties of the reactor. The figure of merit of a heat pipe working fluid is directly dependent on the boiling point and inversely dependent on the atomic weight of the fluid. Lithium-7, with a high boiling point of $1603 \mathrm{~K}$ and a low atomic weight, was chosen as the working fluid. This liquid metal possesses several other desirable characteristics including the highest latent heat of vaporization of all the liquid metals $\left(19.6 \times 10^{6} \mathrm{~J}\right.$ per $\left.\mathrm{kg}\right)$. Lead, which was used in the experiments of Ref. 9, is another possible working fluid.

The evaporator section of each heat pipe is a $15^{\circ}$, pie-shape sector, about $8 \mathrm{~cm}$ long, within the core (fig. 1). The heat pipe has a rectan- 
gular cross section and its internal thickness of $1.2 \mathrm{~cm}$ is representative of the state of the art. The heat flux surfaces are those flat sectors in the radial plane which bound the heat pipe. The use of this heat pipe geometry has some precedence in that heat pipes with rectangular cross sections have been built and designs having bends are being considered.

The curve in Fig. 4 with data taken from Refs. 6, 10, and 11 shows measured evaporator heat flux as a function of lithium-7 temperature. In the current concept, a heat transfer rate of $250 \mathrm{~W} / \mathrm{cm}^{2}$ in the evaporator section (at a lithium temperature of $1770 \mathrm{~K}$ ) is used. Although the heat flux at $1770 \mathrm{~K}$ can be larger, the value $\left(250 \mathrm{~W} / \mathrm{cm}^{2}\right)$ is considered an average resulting from the radial power variation.

The emitter heat pipe wedges may have to be rounded at the outer end (periphery of the core) to provide proper vapor and fluid flow within the pipe. During its passage through and outside the radial reflector, the emitter heat pipe becomes an elliptical cylinder and is assumed to operate adiabatically within the reflector. The choice of an elliptical cross section is influenced by two limitations. First, the heat density in the heat pipe is assumed to be limited to $5 \mathrm{~kW} / \mathrm{cm}^{2}$ of heat pipe cross sectional area. This type of limitation arises in the evaporation and capillary pumping phases of the heat pipe operation. Exceeding this limit can result in burnout of the heat pipe and subsequent failure as a heat transfer unit. A circular cross section with a diameter equal to the sector thickness $(1.2 \mathrm{~cm})$ cannot satisfy this limit. For a $15^{\circ}$ sector with this cross section, the heat density is $7 \mathrm{~kW} / \mathrm{cm}^{2}$. Consequently a larger cross sectional area is needed. However, the loss of 
neutrons from the core through the heat pipe passages can be appreciable so that a minimal cross section, subject to the heat flux limitation, should be used. Secondly, since a certain diode area is needed for each heat pipe, the larger perimeter permits the radial length of heat pipe surrounded by thermionic diodes to be shorter, providing a more compact. reactor.

The elliptical cross section of the heat pipe (fig. 5) maintains a minor axis which is about equal to the sector thickness $(1.2 \mathrm{~cm})$. This restriction to the sector thickness is imposed to prevent any part of the outer surface of the fuel from being unreflected or, in other words, from having a direct line of sight out of the reactor core. The length of the major axis may approach the peripheral are length of the sector, which for a $15^{\circ}$ sector is about $3 \mathrm{~cm}$.

Once outside the radial reflector, the heat pipes may be flared to an even larger cross section. This portion of the heat pipe will be surrounded concentrically by thermionic diodes. The detailed configuration is discussed in the section, The Thermionic Diodes.

The collectors of the diodes are cooled by another set of heat pipes. The experiments of Kerme (ref. 6) showed that because the vapor pressure of lithium is relatively low, a lithium heat pipe would not operate properly below $1070 \mathrm{~K}$. Therefore, since the collector is at about $1000 \mathrm{~K}$, a different working fluid such as cesium will be needed. Also, because of the lower temperature, a heat pipe material lighter than tantalum may be used.

All collector heat pipes on a given axial level terminate in a common flat disk radiator which encircles the reactor (fig. 1 and 6 ). 
This type of radiator was described in the similar reactor concept of Ref. 2. Fig: 6 is taken directly from Ref. 2 and shows the overall configuration of the system. As far as this figure is concerned, the proposed concept essentially differs only by having 10 radiator disks rather than five.

Each radiator is a shell structure is made of $0.076-\mathrm{cm}-$ thick beryllium. The total radiator weight depends on the radiator configuration. The use of conical radiators with various angles of divergence should allow less radiator surface to be covered by adjacent radiators, thus, reducing the weight of the total radiator. However, the calculation of surface.view factors for radiant heat transfer from conical radiators is beyond the scope of this work and it is not within the purpose of this work to contrive an optimum radiator configuration.

A multiplicity of heat pipes in a cellular disk arrangement, similar to that proposed in Ref. 12, may also be considered if the hollow shell radiator proves unsatisfactory: The pipes would provide more efficient cooling requiring less radiator surface and, thus, might offset the weight penalty incurred by using these multiple fully clad heat pipes.

\section{The Thermionic Diodes}

The thermionic power concept described in this paper uses a cylindrical configuration for the diodes. In Fig. 5, a cross section of the concentric diode-heat pipe configuration is shown. The annular tungsten emitters of the out-of-core diodes encircle but are electrically insulated from the heat pipes, by a sheath of beryllium oxide, as they emerge from the radial"reflector. The annular molybdenum collectors, 
arranged concentrically around the emitters, are cooled by another set of heat pipes which extend into the radiator.

A prototype of a thermionic diode with its emitter heated by a heat pipe and its collector cooled by a heat pipe has been operated (ref. 9). For this prototype, the tungsten emitter was vapor plated on the outside of a cylindrical tantalum heat pipe. The emitter area was $17.5 \mathrm{~cm}^{2}$, and the emitter-collector gap was $0.035 \mathrm{~cm}$. The molybdenum collector was sintered to a niobium-zirconium heat pipe. Working fluids of lead and cesium were used, respectively, for the emitter and collector heat pipes.

In the proposed concept, the tungsten emitter of thickness $0.076 \mathrm{~cm}$ is designed for a heat flux of $45 \mathrm{~W} / \mathrm{cm}^{2}$ at $1770 \mathrm{~K}$, which is representative of presently obtainable performance. The emitter-collector gap $(0.035 \mathrm{~cm})$ is filled with cesium at a reservoir temperature of $600 \mathrm{~K}$. The 0.076 em-thick collector is assumed to operate at about $1000 \mathrm{~K}$. Using the data provided in Ref. 9 for similar diode operating conditions, an output of 0.5 volt at a current density of $10 \mathrm{~A} / \mathrm{cm}^{2}$ of emitter is obtained with a diode efficiency of $11 \%$. In order to provide reliability, for example, in the event of an open circuit, each heat pipe will use several adjacent emitters arranged electrically in parallel.

From a fabrication standpoint, planar thermionic diodes may be preferable to cylinarical diodes. In this radial pancake concept, it would be possible to put planar diodes in the core. For this reason, an alternative configuration using planar in-pile thermionic diodes might be considered. However, a severe limitation exists in 
that thermionic diodes are able to accommodate a maximum of only 80100 watts of heat flux $/ \mathrm{cm}^{2}$. Reference 13 describes an in-pile thermionic conversion system which assumes a representative heat flux of $77 \mathrm{~W} / \mathrm{cm}^{2}$.

Since the in-core diode area is about the same as the heat pipe evaporator area, this $100 \mathrm{~W} / \mathrm{cm}^{2}$ is also the maximum heat flux that could be allowed across a fuel surface into a heat pipe. This contrasts sharply with the $250-300 \mathrm{~W} / \mathrm{cm}^{2}$ heat flux that a heat pipe could accept in the out-of-pile configuration. Consequently, in order to supply the same electric power with in-pile diodes, the core size would have to increase to provide more diode area. If the size is not increased, then the electric output power would be decreased from that of the out-ofpile configuration. Thus, the use of in-pile diodes will create a harsh penalty in terms of reactor size.

The penalty in reactor core size incurred by use of the in-pile concept indicates the overall weight of a shadow-shielded in-pile assembly would be greater than for an equivalent out-of-pile assembly. The relative weights of the two assemblies would not be so clear cut in the case of full or four pi shielding since the protrusion of the heat pipes through the shield would complicate matters.

The Reactivity Control System

A reactivity control system of the in-core poison control rod type is examined, in contrast to the moderator-inert gas-thermal absorber arrangement in Ref. 2. The control mechanism used in the current version of the concept consists of a central rod and a concentric tubular 
sheath of boron-10 carbide along the cylindrical axis of the reactor. Although boron-10 is known primarily as a thermal absorber, its neutron absorption cross section remains sufficiently high in the keV and $\mathrm{MeV}$ regions to enable its use as a fast spectrum reactor control poison. The rod and sheath of boron-10 carbide are separated and cooled by a concentric annular heat pipe running the length of the core. The control absorbers may be separately withdrawn to provide two stages of control. The annular heat pipe would not be withdrawn with the outer sheath but would remain in place in the reactor. When the outer sheath is withdrawn, either it or an auxiliary control sheath poised at the opposite end of the reactor may be used as a safety rod. The sheath provides sufficient reactivity control for startup, including the temperature defect. The rod provides for burnup and fine control. A plan view of this control region is shown in Fig. 7. A radiator for the heat pipe must be provided at the axial end of the reactor and it may be in the conical form described by Salmi (ref. 12).

CHARACTERISTICS OF THE CONCEPT

The calculations performed in this study used the standard computer techniques. The specific computer programs and approximation used are discussed in appendix $B$.

A symmetric section of the cylindrical reactor is shown in Fig. 8 . The dimensions of the configuration are indicated and the numbered materials correspond to the composition indicated in table II. The results and performance characteristics of this power concept are now presented in several categories. 
Reactivity Control

The total reactivity control available from the two control absorbers with the dimensions indicated in Fig. 8, is about 6\%., The outer sheath provides a reactivity change of about $5 \%$ for startup. This is sufficient to bring the reactor from a 2 or $3 \%$ subcritical state to a hot critical (operating) condition, assuming a temperature defect of 1 to $2 \%$ reactivity. The inner rod of boron-10 carbide provides about $1.1 \%$ reactivity for burnup and fine control of the reactor. Variation of the thickness of the inner and outer sheaths can yield different burnup and startup reactivity margins.

Assuming a 2.2 MeV energy release for each [ $\eta$, alpha:] reaction in boron-10 and a gamma heat deposition rate not greater than $10 \mathrm{~W} / \mathrm{g}$, the single annular heat pipe is sufficient to cool an inner rod of boron-10 carbide as well as an outer sheath. The maximum heat density in the annular heat pipe would be $0.75 \mathrm{~kW} / \mathrm{cm}^{2}$. The outer sheath, which is cooled by the annular heat pipe would not exceed the temperature of the fuel when the sheath is inserted at full reactor power.

\section{Power Tailoring}

To achieve uniform thermionic diode operation, it is desirable to zone the reactor so that each axial layer of diodes is at approximately the same temperature. Since heat pipes have the property of integrating the heat input over their length, the heat flux used $\left(250 \mathrm{~W} / \mathrm{cm}^{2}\right)$, which is less than the maximum, should allow for variation in radial power. For the purpose of this study it is assumed that there is enough void in the central part of the fuel element to allow the fuel to redistribute itself so that there will not be excessive hot spots on the surface 
of the evaporators. To perform axial power tailoring, the fuel loading was varied for the fuel disks in order to provide about the same heat flux to each of the 10 axial layers of heat pipes.

The heat flux across each heat pipe surface adjacent to a fuel surface is $250 \mathrm{~W} / \mathrm{cm}^{2}$ at a fuel-heat pipe interface temperature of $1770 \mathrm{~K}$. The highest fuel temperature occurs in the central slabs, where the power peaks occur at the midplane of the fuel slabs. The maximum temperature there is $2250 \mathrm{~K}$, well below the melting point of the $\mathrm{U}^{233} \mathrm{~N}$ $(3120 \mathrm{~K})$. The temperatures were determined using the thermal conductivity of $U^{233} \mathrm{~N}\left(0.26 \mathrm{~W} / \mathrm{cm}^{2}\right.$ at $\left.1270 \mathrm{~K}\right)$ from Ref. 4. Figure 9 shows the axial power profile, with the radial dependence removed, for the unzoned and zoned core. The composition of the fuel disks is given in table II.

The axial power profile at the interior and exterior radii of the zoned core fuel annulus is shown in Fig. 10. The profiles are qualitatively the same but with the interior profiles at a level about $I . I$ and the exterior profile at a level about 0.83 times the average power in the core.

With the control sheath withdrawn, simulating the reactor in operation, the axial power profile was obtained for various stages of rod withdrawal. No depletion studies were performed; an undepleted core is assumed at all stages of withdrawal. The axial power profiles for several stages (full, two-thirds, and one-third insertions) are shown in Fig. 11. The figure indicates the rod has little perturbing effect on axial power profile. In particular, with the rod.withdrawn one-third 
the largest power increase in any slab was $2 \%$. With the rod withdrawn two-thirds the profile was essentially the same as for the one-third withdrawn case.

\section{Heat Pipe Geometry}

At a heat flux of $250 \mathrm{~W} / \mathrm{cm}^{2}$, the total power deposited into each $15^{\circ}$ sector heat pipe is $8.06 \mathrm{~kW}$. If the heat pipe cross section were circular with internal diameter of $1.2 \mathrm{~cm}$ as it enters the radial reflector the heat density would be about $7 \mathrm{~kW} / \mathrm{cm}^{2}$ which exceeds the $5 \mathrm{~kW} / \mathrm{cm}^{2}$ limit. Furthermore, if a diode heat flux of $45 \mathrm{~W} / \mathrm{cm}^{2}$ is assumed then the diode area necessary for each heat pipe is $179 \mathrm{~cm}^{2}$. If the diodes are mounted around the circular perimeter of a $1.3-\mathrm{cm}-$ diameter heat pipe, the perimeter would be about $4.1 \mathrm{~cm}$, requiring a 44-cm radial extension to accommodate sufficient diode area.

However, using an elliptical cross section (fig. 5), with a minor axis of $1.2 \mathrm{~cm}$ and a major axis of $2.4 \mathrm{~cm}$, the heat density in the heat pipe is reduced to about $3.6 \mathrm{~kW} / \mathrm{cm}^{2}$. These dimensions which are used in this study also hold the neutron leakage to an acceptable level.

While external dimensions of 1.3 and $2.5 \mathrm{~cm}$ for an elliptical cross section are satisfactory for passage through the radial reflector, they are not entirely suitable for a diode mount. It is desirable to make the reactor assembly as compact as possible, and, consequently, the length of the radial extension needed for diode mounting is of concern. The minimum radial extension for diode mounting is $29 \mathrm{~cm}$ "beyond the radialireflector for such a cross section. However, outside the radial : reflector, there is no fuel, and the heat pipe sector arc length: 
has increased to $4.6 \mathrm{~cm}$. Therefore, the elliptical cross section is flared out to dimensions of 2.0 and $4.0 \mathrm{~cm}$. This provides a larger perimeter for diode mounting (about $9.9 \mathrm{~cm}$ ), and the diodes thus require an extension of only $18 \mathrm{~cm}$.

On the other hand, if $10^{\circ}$ sector heat pipes were used, with circular radial extensions, each would carry $5.38 \mathrm{~kW}$ at a heat density of $4.8 \mathrm{~kW} / \mathrm{cm}^{2}$. If the cross section, upon emerging from the radial reflector, were flared out to elliptical dimensions of 2.0 and $2.4 \mathrm{~cm}$ the radial extension needed for a diode area of $119 \mathrm{~cm}^{2}$ would be $17 \mathrm{~cm}$. Thus, for a small attendant reduction in radiator and shield weight resulting from their smaller radius, the use of $10^{\circ}$, rather than $15^{\circ}$ sectors, would require $50 \%$ more heat pipes.

Flectrical System Output

Since each fully heated $15^{\circ}$ heat pipe requires a total diode area of about $180 \mathrm{~cm}^{2}$, four diodes of $45 \mathrm{~cm}^{2}$ each may be used. Because the heat pipes on each axial end of the reactor receive heat from only one side only two diodes will be needed per heat pipe on these levels. Thus, although there are 240 sector heat pipes in the reactor, there are only 216 equivalent full power heat pipes. The diodes on each heat pipe will be electrically in parallel, producing 0.5 volt and, for four diodes, $1800 \mathrm{~A}$. Calculations indicate that a beryllium oxide sheath, 0.058-cm thick, could hold the integrated electrical leakage to 5\% (current loss) with a series voltage of 50 volts across the diodes. To achieve this 50 volt output, it is necessary to couple the electrical output from two 
ajacent heat pipes in parallel. The total system output is then $3600 \mathrm{~A}$ at 54 volts for $194 \mathrm{kWe}$, neglecting losses.

However, there are several losses which must be considered. The assumed electrical leakage of $5 \%$ is charged as a current loss (in the insulator) with an attendant $5 \%$ power loss. The diode circuitry is assumed to be optimized, a condition for which the power loss due to lead arop is generally about the same as the diode efficiency (11\%): Also, each diode has an $I^{2} R$ power loss of about $16 \%$ in the tungsten emitter and molybdenum collector.

The three loss mechanisms considered constitute a 32\% power loss. The net system output thus is $131 \mathrm{kWe}$ at 38.3 volts and $3420 \mathrm{~A}$.

\section{Radiators}

The radiators for this concept are a series of flat disks (fig. 6) with an inside radius of $0.36 \mathrm{~m}$. The outside radii are based on calculations assuming that $90 \%$ of the power is radiated from the beryllium radiator area. In addition to a surface emissivity of 0.9 for beryllium a sink temperature of $O K$ is assumed for deep space. A surface view factor, representing the fraction of a radiating surface not covered by an adjacent radiator, is also used. Since the radiator configuration (fig. 6) is similar to that in Ref. 2, the same factor of 0.85 is used. Each of the end radiators is designed to radiate $97 \mathrm{~kW}$; all other radiators must radiate $194 \mathrm{~kW}$. The resulting outside radii are 0.96 , $1.59,2.03,2.39$, and $2.70 \mathrm{~m}$. This brings the overall diameter of the power system to $5.4 \mathrm{~m}$. In determining the size and weight of the whole radiator, no allowance was made for structural (e.g., struts) support materials. 


\section{CONCLUDING REMARKS}

A summary of reactor, heat pipe, and thermionic diode operating conditions is presented in table III. This shows that a cylindrical reactor core which is only $23.4 \mathrm{~cm}$ in diameter and $31.0 \mathrm{~cm}$ long can produce about $130 \mathrm{~kW}$ of electricity at a potential of about 38 volts. The volume fractions and estimated weights of various materials comprising the power system are listed table IV. The calculated total weight of the materials for the reactor, the diodes, and the radiator is about $800 \mathrm{~kg}$ excluding any shielding.

In order to allow more uniform heat flux to the thermionic diodes, the axial power distribution is tailored, by nonuniform distribution of fuel, to within 5\%. A boron-10 carbide central control rod and concentric sheath provide respective reactivity changes of about $1.1 \%$ for burnup and fine control and about $5 \%$ for startup.

It appears that the heat pipe will be able to carry away about $300 \mathrm{~W}$ of heat from every square centimeter of in-pile heat transfer surface, which is about the same as the practical heat flux limit on forced convection liquid metal system. Furthermore, the heat pipe can distribute this heat flux over a much larger heat transfer surface external to the reactor. This is important since it seems that the thermionic diode, even at quite extreme temperatures, will be limited to a thermal power input less than $100 \mathrm{~W} / \mathrm{cm}^{2}$ of emitter area. This limitation to $100 \mathrm{~W} / \mathrm{cm}^{2}$ presents a considerable disadvantage for an in-pile thermionic concept because a nuclear reactor is capable of producing much higher heat fluxes. Thus, for the same output power, the out-of-pile thermionic 
reactor, when shadow shielded, can be smaller and lighter than the equivalent in-pile assembly.

An added advantage is that the use of heat pipes extending outside the reactor core directly to radiators eliminates the need for a secondary liquid cooling loop.

\section{APPENDIX A}

ALTERNATE FUELS

If uranium-235 nitride ( $\mathrm{U}^{235} \mathrm{~N}$ ) is used as the fuel (with the same volume fraction as for the $\mathrm{U}^{233} \mathrm{~N}$ case) and only the reactor diameter is varied, the core diameter must increase to $36 \mathrm{~cm}$ in order to obtain a critical configuration. The volume of $\mathrm{U}^{235_{\mathrm{N}}}$ needed is thus 2.5 times the amount of $U^{233} \mathrm{~N}$ necessary. Since the axial geometry and length is the same the power output of the $U^{235} \mathrm{~N}$ core also increases by about two. and one-half times over the $U^{233} \mathrm{~N}$ output. Thus, a $\mathrm{U}^{235_{\mathrm{N}}}$ core would have dimensions of $31 \mathrm{~cm}$ (length) and $36 \mathrm{~cm}$ (diameter); it would supply a power output of $325 \mathrm{kWe}$ and would require $145 \mathrm{~kg}$ of $\mathrm{U}^{235} \mathrm{~N}$. By comparison, the $U^{233} \mathrm{~N}$ core has dimensions of $31 \mathrm{~cm}$ (length) and $23.4 \mathrm{~cm}$ (diameter); it can provide $130 \mathrm{kWe}$ of electric power and uses $58 \mathrm{~kg}$ of $\mathrm{U}^{233} \mathrm{~N}$. Of course, for the $\mathrm{U}^{235} \mathrm{~N}$ core the size and weight of the diode arrays, radiators, and reflectors would be accordingly increased from the $\mathrm{U}^{233} \mathrm{~N}$ case.

The use of plutonium-239 nitride $\left(\mathrm{Pu}^{239} \mathrm{~N}\right)$ would result in a core of about the same dimensions, power output, and fuel mass as the $U^{233} \mathrm{~N}$ case. Furthermore, with a nitrogen overpressure of 1 atmosphere $\left(10.13 \mathrm{~N} / \mathrm{cm}^{2}\right.$ ), the melting point of $\mathrm{Pu}^{239} \mathrm{~N}$ is $2870 \mathrm{~K}$ (compared to a maximum fuel temperature of $2250 \mathrm{~K}$ ). 
APPENDIX B

METHOD OF CALCULATIONS

The composition of the materials and their homogenized atom densities are presented in table II. Several fuel slab compositions which are used in performing the axial zoning are shown in this table.

Cross sections for the calculations were obtained from the GAM-II multigroup compilation (ref. 14). Thirteen fast groups were used, the structure of which is shown in table V. Most of the spatial calculations were performed with 13 groups in one dimension (1-D) in the $S_{4-P_{O}}$ (transport correct) approximation using the TDSN program (ref. 15). However, two-dimensional $r-z$ calculations were made, using 4 groups, to provide normalization for the I-D calculations and to determine power profile for control rod withdrawal stages. The 2-D geometry is very closely that shown in Fig. 8 and the reduced group structure used is indicated in table $V$.

\section{REF'ERENCES}

1. ANON., "Space Power Systems Advanced Technology Conference", NASA SP-131, pp. $272-275$ (1966).

2. C. A. HEATH and E. LANIZ, "Nuclear Thermionic Space Power System Concept Employing Heat Pipes," NASA TN D-4299 (1968).

3. C. S. BARNETT, "An Out-of-Pile Heat Pipe Thermionic Space-Power Concept", Trans. Am. Nucl. Soc. 9, 338 (1966).

4. M. ALIBUTT and R. M. DELL, "Chemical Aspects of Nitride, Phosphide and Sulfide Fuels", J. Nucl. Materials, V. 24, I (1967).

5. K. T. FELDMAN, JR. and G. H. WHITING, "The Heat Pipe," Mech. Eng. 89 $30(1967)$. 
6. J. E. KEMME, "Heat Pipe Capability Experiments," LA-3585-MS, Los Alamos Scientific Lab. (1966).

7. T. P. COTTER, "Theory of Heat Pipes," LA-3246-MS, Los Alamos Scientific Lab. (1965).

8. D. K. ANAND, "On the Performance of a Heat Pipe," J. Spacecraft and Rockets $\underline{3}, 763$ (1966).

9. C. A. BUSSE, R. CARON, and C. CAPHLLETPI, "Prototypes of Heat Pipe Thermionic Converters for Space Reactors," presented at the International Conference on Thermionic Electrical Power Generation, European Nuclear Energy Agency and Institution of Electrical Engineers, London (Sept. 20-25, 1965).

10. W. B. HAII, "Heat-Pipe Experiments." Thermionic Conversion Speclalist Conference, IEEE, pp. 337-340 (Oct. 25-27, 1965).

11. J. DEVERALI and J. KEMME, "High Thermal Conductance Devices Utilizing the Boiling of Iithium or Silver," LA-3211, Los Alamos Scientific Lab. ( 1965$)$.

12. E. W. SAIMI, "A Study of a Nuclear Thermionic Propulsion System," Paper No. 67-229, AIAA (1967).

13. H. YACOBUCCI, "A Preliminary Study of Thermionic Reactor Cores Composed of Short-Length Externally-fueled Diodes," Proposed NASA Technical Note.

14. G. D. JOANOU and J. S. DUDEK, "GAM-II. A $B_{3}$ Code for the Calculation of Fast Neutron Spectra and Associated Multigroup Constants," GA-4265, General Dynamics Corp. (1963).

15. C. E. BARBER, "A Fortran IV Two-Dimensional Discrete Angular Segmentation Transport Program," NASA TN D-3573 (1966). 
TABLE I. - COMPARISON OF ELECTROMAGIVETIC COOLANT LOOP WITH HEAT PIPES

\begin{tabular}{|c|c|}
\hline Electromagnetic pumped loop & Heat pipes \\
\hline \multicolumn{2}{|c|}{ 1. Fluid loop characteristics } \\
\hline $\begin{array}{l}\text { One or more pumps per loop. Pres- } \\
\text { surizer and liquid metal purfier } \\
\text { required. System not permanently } \\
\text { sealed. Single leak in system } \\
\text { catastrophic. }\end{array}$ & $\begin{array}{l}\text { No mechanical pumps--many perma- } \\
\text { nently sealed individual loops. } \\
\text { System designed so that a single } \\
\text { leak can only effect one heat } \\
\text { pipe loop. }\end{array}$ \\
\hline \multicolumn{2}{|c|}{ 2. Heat transfer } \\
\hline $\begin{array}{l}\text { Fluid temperature across core is } \\
\text { an inverse function of pumping } \\
\text { power. }\end{array}$ & Isothermal \\
\hline \multicolumn{2}{|c|}{ 3. Pumping characteristics } \\
\hline $\begin{array}{l}\text { EM pumps inefficient and require } \\
\text { electricity. Allowable magnet } \\
\text { temperature is limited to below } \\
\text { Curie temperature. }\end{array}$ & $\begin{array}{l}\text { Heat pipes more efficient. Use } \\
\text { thermal energy directly. }\end{array}$ \\
\hline \multicolumn{2}{|c|}{ 4. Pumping malfunction } \\
\hline Would required pump switching & $\begin{array}{l}\text { No pumps. Malfunction in indi- } \\
\text { vidual heat pipe is provided for. }\end{array}$ \\
\hline \multicolumn{2}{|c|}{ 5. After heat removal } \\
\hline $\begin{array}{l}\text { Reactor has to be operated at a } \\
\text { considerable power level to gen- } \\
\text { erate enough electricity to run the } \\
\text { pump. }\end{array}$ & $\begin{array}{l}\text { After heat automatically radiated } \\
\text { away without core meltdown. }\end{array}$ \\
\hline \multicolumn{2}{|c|}{ 6. Restart } \\
\hline $\begin{array}{l}\text { Heaters for the complete system } \\
\text { will be required to remelt the } \\
\text { liquid metal without bursting the } \\
\text { pipes. }\end{array}$ & $\begin{array}{l}\text { Should be able to restart without } \\
\text { the use of external heaters. }\end{array}$ \\
\hline
\end{tabular}




\section{4}

TABLE II. - COMPOSITION OF REACTOR MATERIALS

\begin{tabular}{|c|c|c|c|}
\hline Component ${ }^{a, b}$ & Composition & Nuclide & $\begin{array}{l}\text { Nuclear density } \\
\text { atom } /(\mathrm{b})(\mathrm{m})\end{array}$ \\
\hline Fuel (1) & $\begin{array}{l}0.547 \mathrm{U}^{233 \mathrm{~N}} \\
.189 \mathrm{Void} \\
.264 \mathrm{~W}\end{array}$ & $\left\{\begin{array}{c}N \\
U^{233}\end{array}\right\}$ & $\begin{array}{l}1.908 \\
1.668\end{array}$ \\
\hline Fuel (2) & $\begin{array}{l}0.556 \mathrm{U}^{233} \mathrm{~N} \\
.188 \mathrm{Void} \\
.256 \mathrm{~W}\end{array}$ & $\left(u^{233}\right)$ & $\begin{array}{l}1.668 \\
1.618\end{array}$ \\
\hline Fuel (3) & $\begin{aligned} 0.575 \mathrm{U}^{233} \mathrm{NN} \\
.184 \text { Void } \\
241 \mathrm{~W}\end{aligned}$ & $\left\{\begin{array}{c}\mathrm{N} \\
U^{233}\end{array}\right\}$ & $\begin{array}{l}2.007 \\
1.523\end{array}$ \\
\hline Fuel (4) & $\begin{array}{l}0.631 \mathrm{U}^{233} \mathrm{~N} \\
.173 \mathrm{Void} \\
.196 \mathrm{~W}\end{array}$ & $U^{233}$ & $\begin{array}{l}2.204 \\
1.239\end{array}$ \\
\hline Fuel (5) & $\begin{array}{l}0.723 \mathrm{U}^{233} \mathrm{~N} \\
.156 \text { Void } \\
.121 \mathrm{~W}\end{array}$ & $\begin{array}{c}\left\{U^{233}\right\} \\
W\end{array}$ & $\begin{array}{r}2.533 \\
.7647\end{array}$ \\
\hline
\end{tabular}


TABLE II. - COMPOSITION OF REACTOR MATERIALS (con't)

\begin{tabular}{|l|c|c|c|}
\hline \multicolumn{1}{|c|}{ Componentä, } & Composition & Nuclide & $\begin{array}{c}\text { Nuclear density } \\
\text { atom/(b)(m) }\end{array}$ \\
\hline Heat pipe (6) & $\begin{array}{c}0.077 \mathrm{Ta} \\
.923 \mathrm{Void}\end{array}$ & Natural Ta & 0.4253 \\
\hline Eontrol absiorber (7) & $\mathrm{B}_{4}^{10_{\mathrm{C}}}$ & $\left\{\begin{array}{l}\mathrm{B}^{10} \\
\mathrm{C}\end{array}\right.$ & $\begin{array}{c}11.64 \\
2.91\end{array}$ \\
\hline $\begin{array}{l}\text { Axial radial re- } \\
\text { flector (8) }\end{array}$ & Mo & Natural Mo & 6.4 \\
\hline $\begin{array}{l}\text { Homogenized radial } \\
\text { reflector and heat } \\
\text { pipe (9) }\end{array}$ & $\begin{array}{l}.551 \text { Mo } \\
.449 \text { Void }\end{array}$ & Natural Mo & 3.526 \\
\hline
\end{tabular}

aThe lithium-7 in the heat pipe was neglected.

$\mathrm{b}_{\text {See }} \mathrm{Fig}$. 8 for the number assignment. 
TABLE III. - SUMMARY OF OPERATING CHARACTERISTICS OF THE POWER SYSTEM

Reactor:

Fuel volume fraction

0.334

Number of fuel layers

Length incluaing $20 \mathrm{~cm}$ of axial reflector, $\mathrm{m}$

.51

Diameter including $12 \mathrm{~cm}$ of radial refl., $\mathrm{m}$

.355

Diameter of largest radiator, $m$

5.4

Maximum fuel temperature, $K$

2250

Fuel clad temperature, $\mathrm{K}$

1770

Total thermal power, MW

1.74

Power density in full core, $\mathrm{W} / \mathrm{cm}^{3}$

Heat pipes:

Number of sectors per axial level

Heat flux into heat pipe, $\mathrm{W} / \mathrm{cm}^{2}$

Total heat per full powered sector, $\mathrm{kW}$

Total heat per layer, $\mathrm{kW}$

8.06

Maximum heat density (in radial reflector), $\mathrm{kW} / \mathrm{cm}^{2}$

193.5

Radial extension for diodes, $m$

3.56

Total number of heat pipes at full power

Total number of heat pipes at half power (layers at ends of core)

0.18

192

48

Thermionid diodes:

Number of emitters per full power heat pipe

Total number of diodes

Temperature of emitter, $K$

1770

Temperature of collector, $\mathrm{K}$

Fmitter and collector thickness, $\mathrm{cm}$

Emitter area per diode, $\mathrm{cm}^{2}$

Current density, $\mathrm{A} / \mathrm{cm}^{2}$

Emitter perimeter, $\mathrm{cm}$

Emitter length, $\mathrm{cm}$

Heat flux at diode, $w / \mathrm{cm}^{2}$

Emitter electrical power density, $W / \mathrm{cm}^{2}$

Diode efficiency, percent

Electrical power per diode, $W$

Output voltage, $\mathrm{V}$ 
TABLE III. - SUMMARY OF OPERATING CHARACTERISTICS OF THE POWER SYSTEM (con't)

Systyem output:

Total voltage, $\mathrm{V}$

Total output current, A

Total power output, $\mathrm{kW}$

Power lost through leakage, (5\%) $\mathrm{kW}$

Power lost through leads (11\%), $\mathrm{kW}$

Power lost through $\mathrm{I}^{2} \mathrm{R}$ drop, $(\sim 16 \%)$

Net output power, $\mathrm{kW}$

5 percent current loss through leakage, A

Net output current, A

Net output potential, V

Overall efficiency, percent 
TABLE IV. - ESTIMATED WEIGHTS OF SYSTEM COMPONEINTS

\begin{tabular}{|c|c|c|c|}
\hline Component & Material & $\begin{array}{l}\text { Volume; } \\
\mathrm{cm}^{3}\end{array}$ & $\begin{array}{l}\text { Weight, } \\
\text { kg }\end{array}$ \\
\hline Fuel & $\begin{array}{l}\text { Uranium-233 nitride } \\
\text { Tungsten }\end{array}$ & 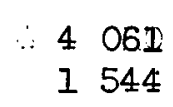 & $\begin{array}{l}58.2 \\
29.8\end{array}$ \\
\hline Heat pipe & $\begin{array}{l}\text { Tantalum (in core) } \\
\text { Tantalum (extension) } \\
\text { Lithium }\end{array}$ & $\begin{array}{ll} & 713 \\
2 & 650 \\
5 & 085\end{array}$ & $\begin{array}{r}11.8 \\
44.0 \\
2.5\end{array}$ \\
\hline Reflector & Molybdenum & 20210 & 206.0 \\
\hline Diode & $\begin{array}{l}\text { Tungsten (emitter) } \\
\text { Molybdenum (collector) }\end{array}$ & $\begin{array}{ll}2 & 950 \\
2 & 950\end{array}$ & $\begin{array}{l}57.0 \\
30.1\end{array}$ \\
\hline Radiator & Beryllium & 190000 & 351.5 \\
\hline Control system & Boron-10 Carbon & 1167 & 2.9 \\
\hline Total & & & 794 \\
\hline
\end{tabular}


TABLE V. - ENERGY GROUP STRUCTURE

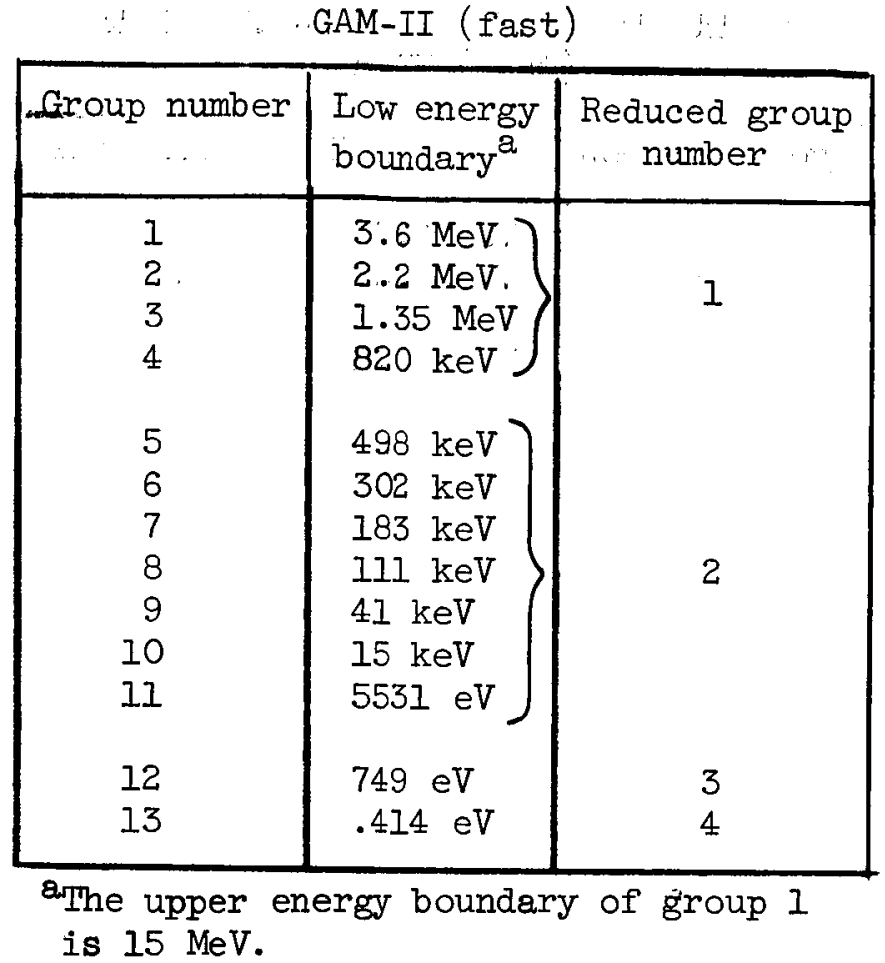


CUTAWAY OF A THERMIONIC-HEAT PIPE SPACE POWER SYSTEM

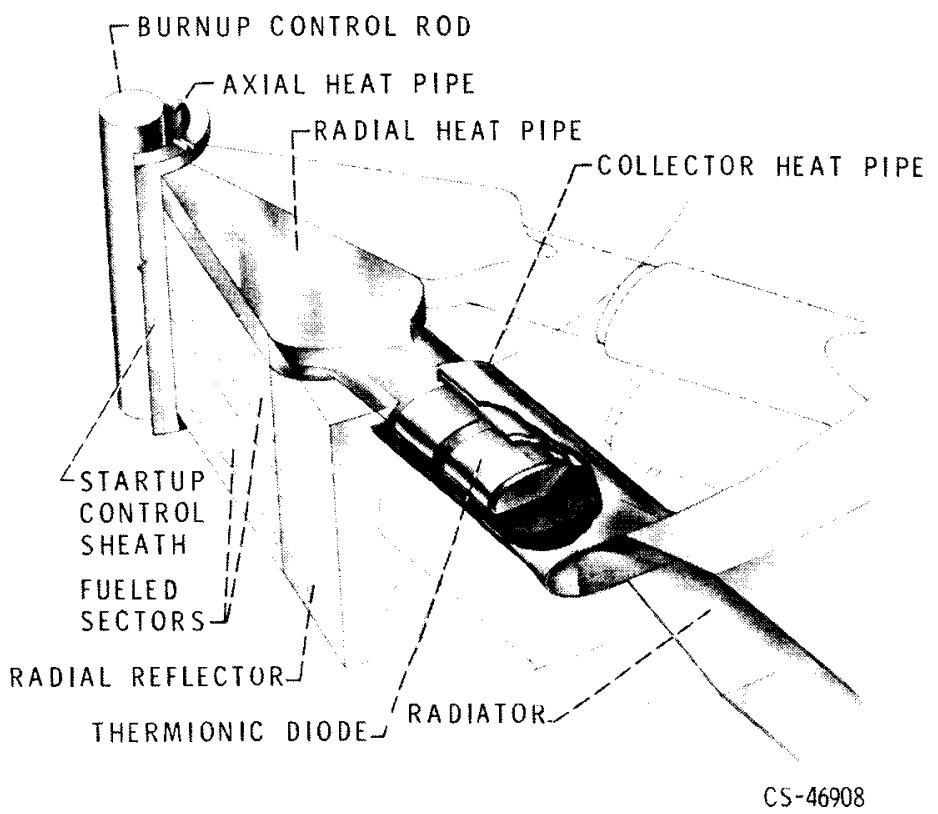

Figure I.

PORTION OF ONE QUADRANT OF THE REACTOR SHOWING THE PERIPHERY OF THE REACTOR CORE WITH RADIAL REFLECTOR REMOVED

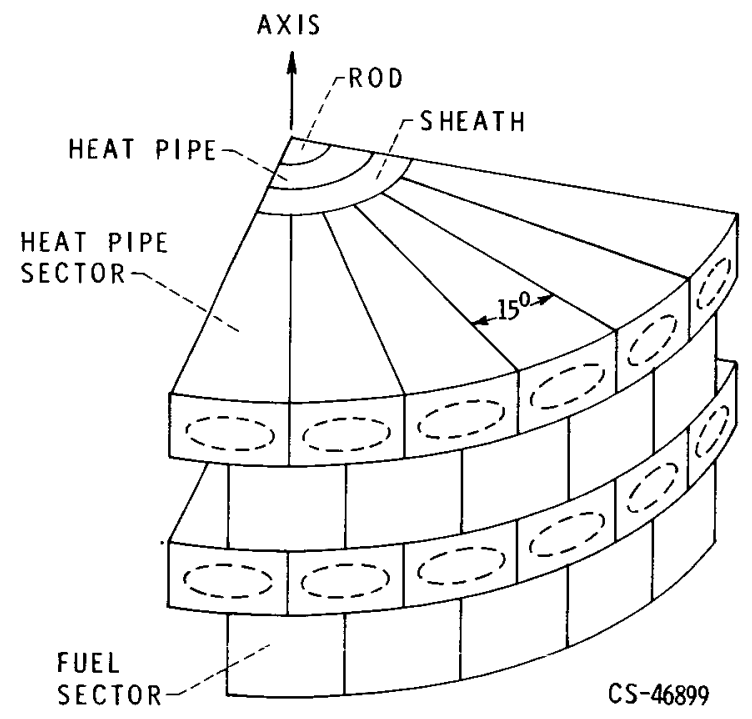

Figu re 2. 


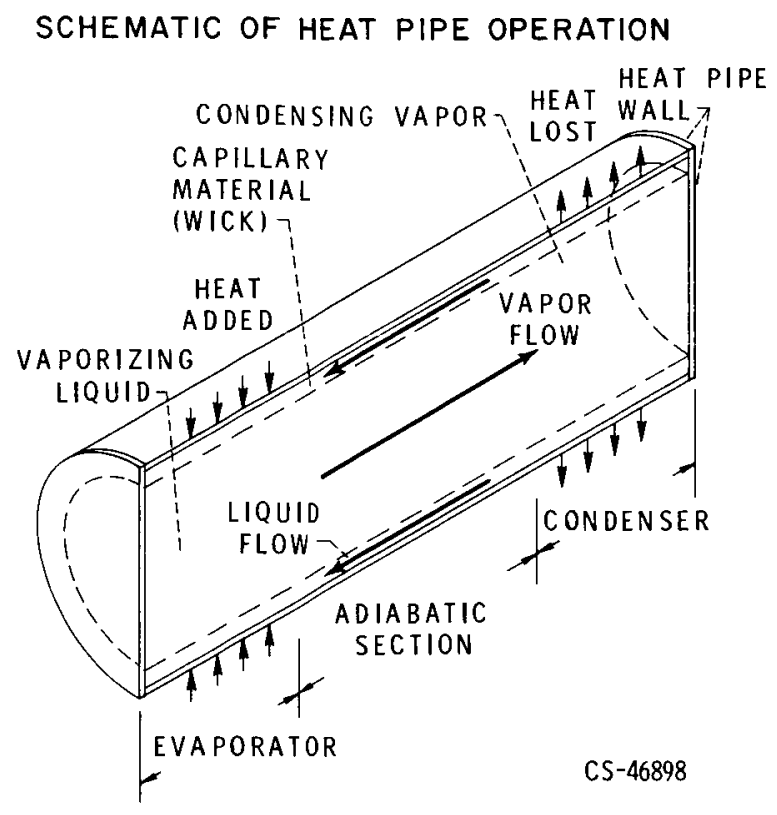

Figure 3.

MEASURED EVAPORATIVE HEAT FLUXES

IN LITHIUM HEAT PIPES

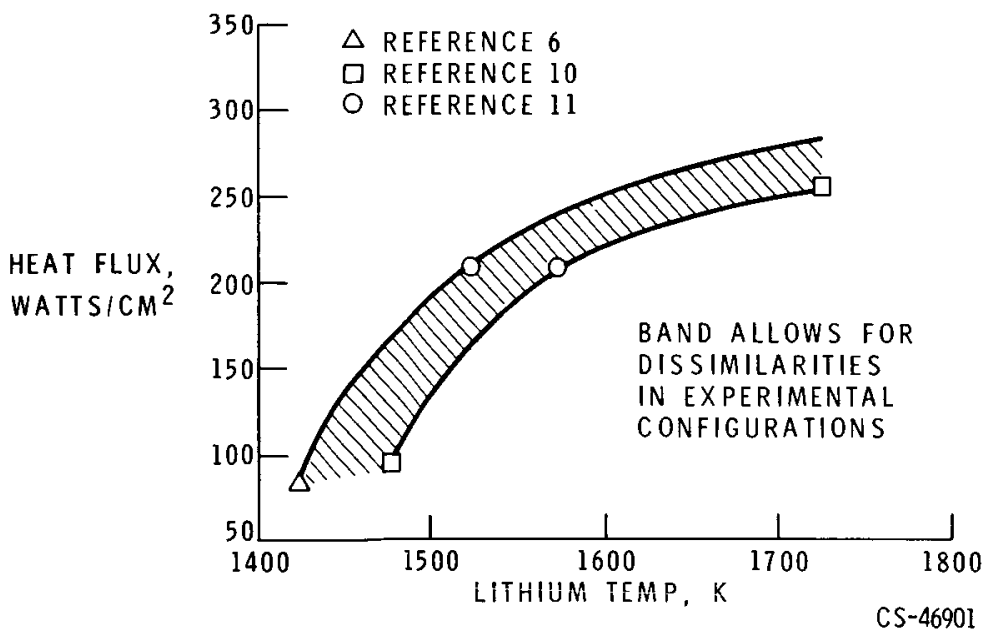

Figure 4. 


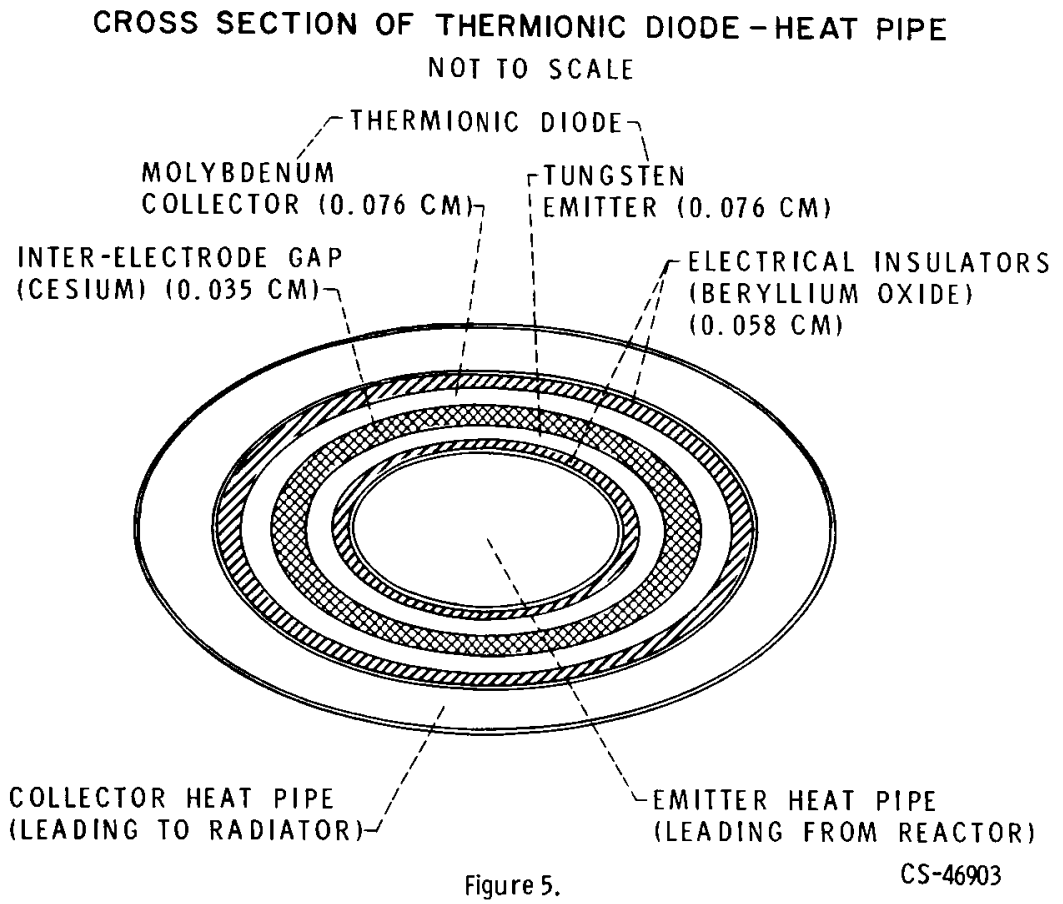

RADIAL HEAT PIPE-THERMIONIC REACTOR SYSTEM

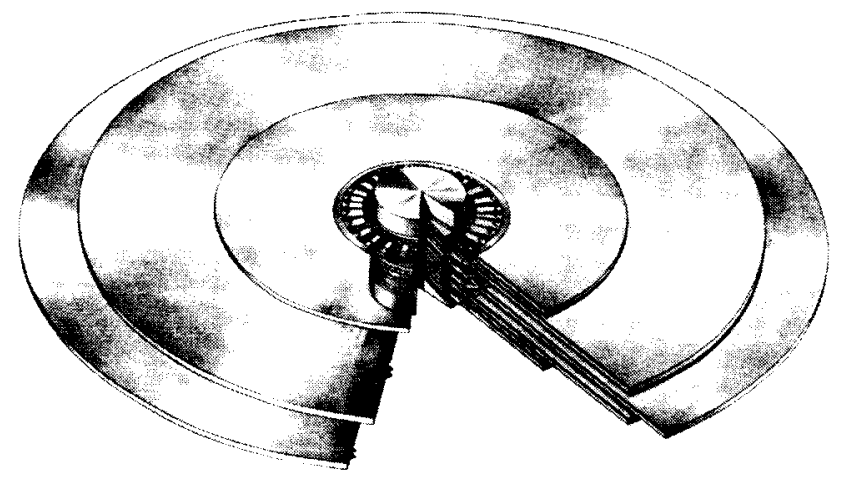

CS -46907

Figu re 6. 
PLAN VIEW OF CENTRAL CONTROL REGION

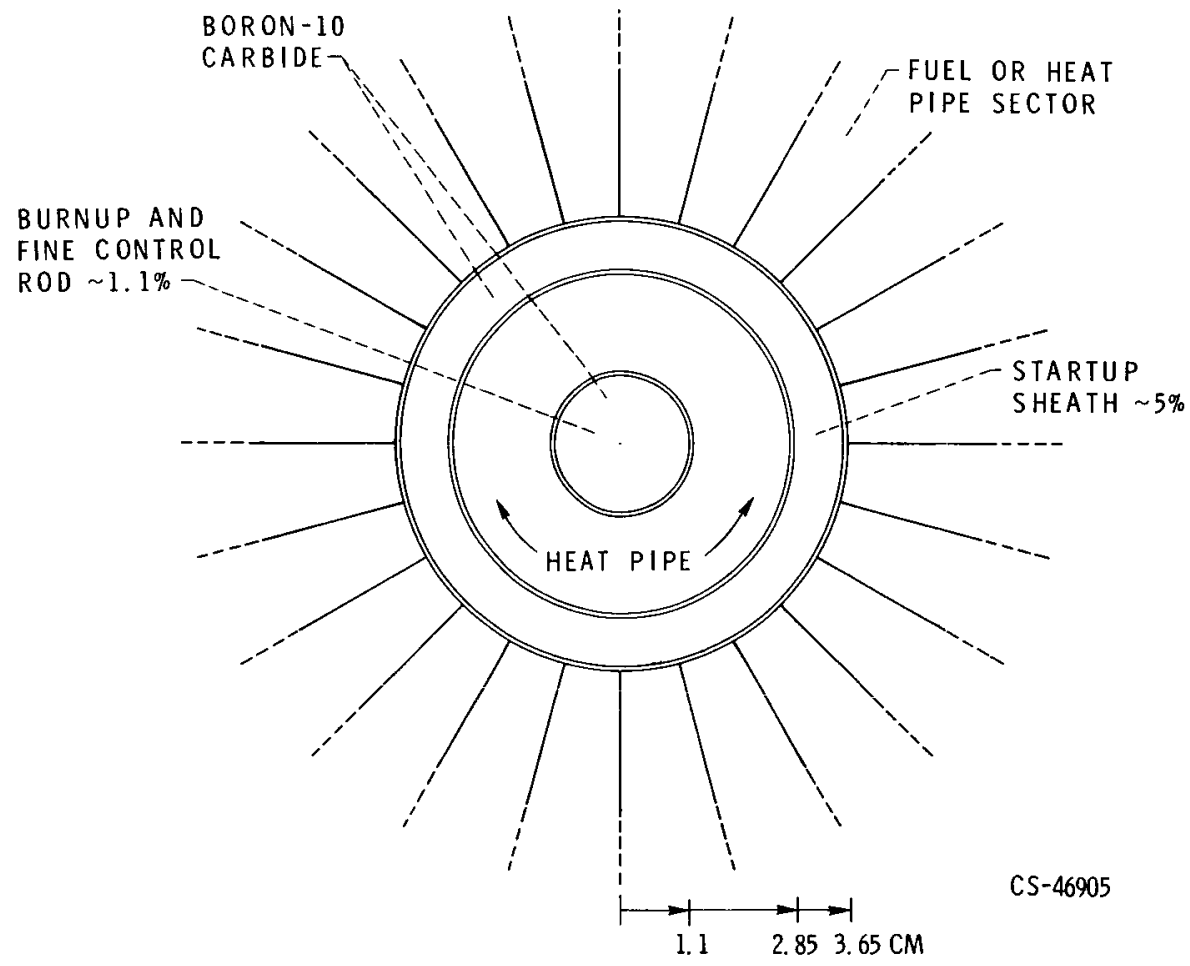

Figure 7. 
REACTOR CONFIGURATION INCLUDING THE $r-z$ GEOMETRY USED FOR THE TWO-DIMENSIONAL CALCULATIONS

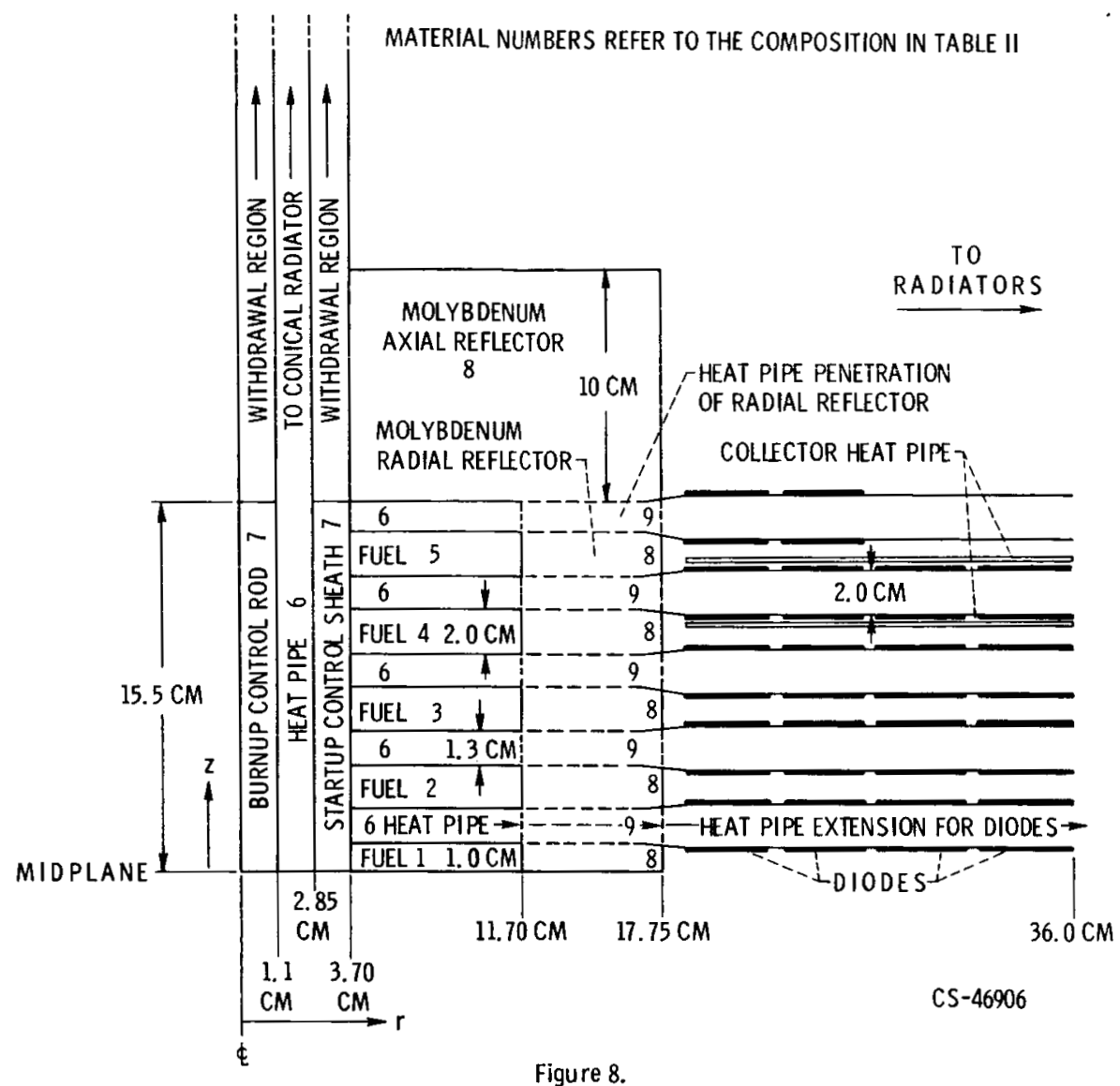

Figure 8.

AXIAL POWER PROFILES FOR THE ZONED AND UNZONED CONFIGURATIONS

UNZONED CONCENTRATION IS THE SAME AS THE ZONED

CONCENTRATION IN THE OUTER SLAB

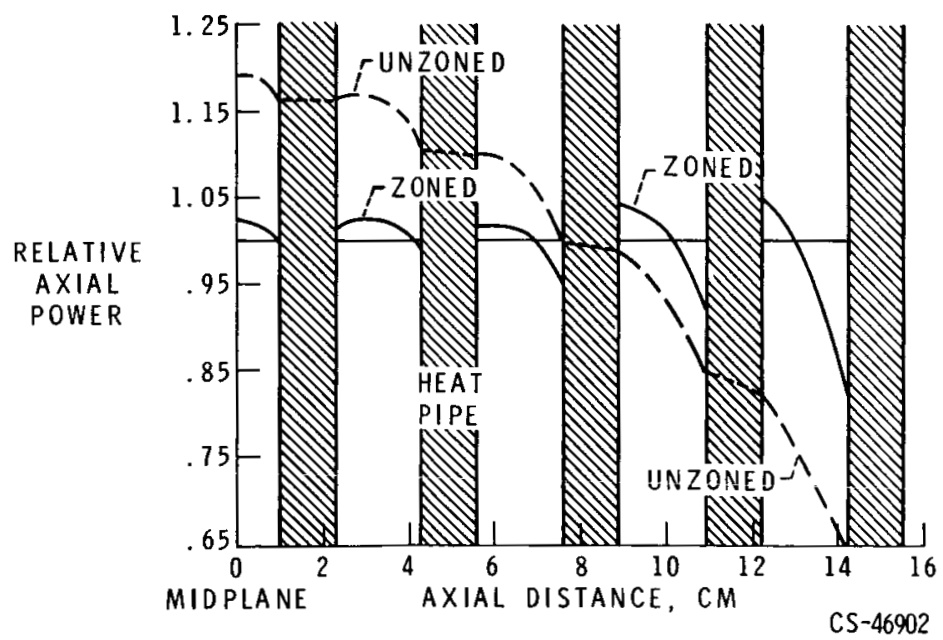

Figure 9. 
AXIAL POWER PROFILE AT THE INTERIOR AND EXTERIOR RADIUS OF THE FUEL ANNULUS

THE REACTOR IS AXIALLY ZONED

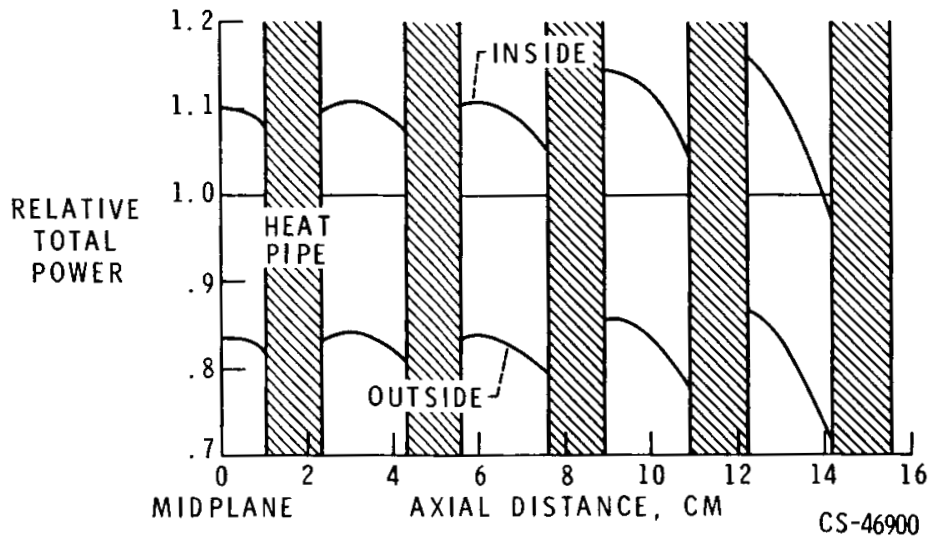

Figure 10.

AXIAL POWER PROFILE FOR VARIOUS STAGES OF ROD WITHDRAWAL

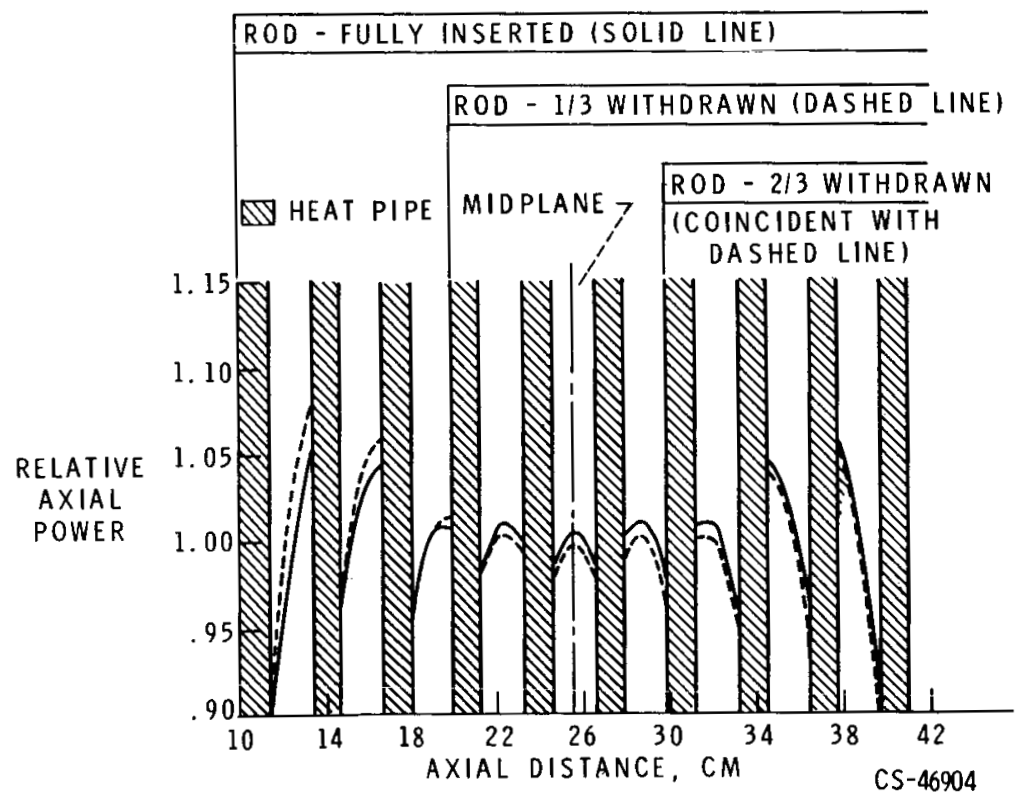

Figure 11. 